\title{
Effects of ion irradiation in the thermal oxidation of $\mathrm{SiC}$
}

\author{
C. Radtke and I. J. R. Baumvol \\ Instituto de Física, UFRGS, Av. Bento Gonçalves 9500, Porto Alegre, RS, Brazil 91509-900 \\ F. C. Stedile* \\ Instituto de Química, UFRGS, Av. Bento Gonçalves 9500, Porto Alegre, RS, Brazil 91509-900
}

(Received 22 May 2002; published 31 October 2002)

\begin{abstract}
We investigated the thermal growth of $\mathrm{SiO}_{2}$ films on $6 \mathrm{H}-\mathrm{SiC}$ (0001) samples irradiated with $170 \mathrm{keV} \mathrm{Ar}^{+}$ ions. Electronic, compositional, and structural features arisen from the irradiation process were accessed. All results are compared to those of nonirradiated substrates, revealing major differences due to ion bombardment such as the enhanced rate of oxidation, the variation of roughness of both oxide surface and $\mathrm{SiO}_{2} / \mathrm{SiC}$ interface, and of the stress in the formed oxide layer. Modifications on the electronic structure and crystallographic characteristics of the substrate underneath the oxide were also observed in samples in which the ion irradiation damaged layer was only partially consumed by the oxidation step. The present work evidences that a careful choice of sample preparation conditions is necessary to avoid undesired characteristics in the final $\mathrm{SiO}_{2} / \mathrm{SiC}$ structure and points to a way of preventing irradiation related degradation of electrical characteristics while maintaining the high oxidation rate.
\end{abstract}

DOI: 10.1103/PhysRevB.66.155437

PACS number(s): 81.65.Mq, 68.37.Ps, 68.49.Sf, 79.60.Jv

\section{INTRODUCTION}

Silicon carbide $(\mathrm{SiC})$ is the material of choice for highpower, high-temperature, high-speed, and/or high frequency electronic devices. ${ }^{1,2}$ This is due to certain properties of this material including wide band gap, high breakdown electric field, high thermal conductivity and high-saturated electron drift velocity. ${ }^{3,4}$ However, the feature that really sets SiC apart from other wide band-gap semiconductors is the possibility of growing a well-known dielectric film on this material by thermal oxidation, namely, $\mathrm{SiO}_{2}$. This is highly desirable since a substantial part of the technology already developed for $\mathrm{Si}$ can be adapted to the fabrication of $\mathrm{SiC}$ devices. Nevertheless, some barriers must still be overcome. The electrical passivation characteristics of $\mathrm{SiO}_{2}$ thermally grown on $\mathrm{SiC}$ are worse than those of $\mathrm{SiO}_{2}$ on $\mathrm{Si}^{1}$ Various explanations were already proposed to this bad performance, most of them attributing it to carbon present in the oxide, in particular at the $\mathrm{SiO}_{2} / \mathrm{SiC}$ interface. ${ }^{5-8}$ Another processing problem of $\mathrm{SiC}$ is the low oxidation rate of this material: high temperatures and/or long oxidation times have to be used to achieve the desired oxide thickness. ${ }^{3}$

Thus, the increase of the oxide growth rate and the improvement of the electrical quality of the near-interface region of $\mathrm{SiO}_{2}$ on $\mathrm{SiC}$ are critical issues for device fabrication. In an attempt to enhance the oxidation rate of $\mathrm{SiC}$, a couple of techniques were already investigated. Chudoba et al. ${ }^{9}$ studied the oxidation of $\beta$-SiC (100) surfaces modified by deposition of a $\mathrm{Rb}$ monolayer. The oxygen uptake was enhanced by four orders of magnitude in comparison with clean $\beta$-SiC (100) surfaces. In addition to the oxidation rate enhancement, the $\mathrm{Rb}$ overlayer was completely removed from the surface by thermal treatment below $780{ }^{\circ} \mathrm{C}$. Despite the excellent results obtained, this technique is only suitable to grow thin oxides while thicker films $(\sim 30 \mathrm{~nm})$ are needed in actual $\mathrm{SiC}$ devices. In another approach, ion irradiation of $\mathrm{SiC}$ single-crystal samples was used. ${ }^{10-12}$ Oxida- tion kinetics studies of irradiated SiC (Ref. 10) evidenced that the damaged layer oxidizes much faster than crystalline $\mathrm{SiC}$, which allows oxidation at substantially lower temperatures (typically 1100 instead of $1300{ }^{\circ} \mathrm{C}$ ). Despite the larger rate of oxidation, oxide films thermally grown on ion irradiated SiC presented so far an electrical quality inferior ${ }^{13}$ to that of oxides grown on nonirradiated SiC. We tentatively attribute this result to the fact that the damaged layer was not totally oxidized. In order to test this hypothesis, an atomic scale investigation of the reasons for these characteristics was undertaken. The aim is to modify conveniently the irradiation and oxide growth processes such that they lead to better quality oxides while maintaining the high oxidation rate.

In the present work a set of samples was prepared in order to portrait different stages of thermal oxide growth on $\mathrm{SiC}$ samples amorphized by irradiation with energetic $\mathrm{Ar}^{+}$ions. Chemical composition was probed as a function of depth in these $\mathrm{SiO}_{2}$ films thermally grown on Ar-bombarded $\mathrm{SiC}$ substrates. For this purpose, x-ray photoelectron spectroscopy (XPS) analyses in conjunction with step-by-step etching of the oxides were accomplished. The same procedure was carried out with a nonirradiated sample for comparison. Rutherford backscattering spectrometry in channeling geometry ( $c$-RBS) was used to probe the crystallinity of the substrate underneath the oxide and to determine the oxide thickness. Atomic force microscopy (AFM) scans were performed to analyze the surface morphology of the oxide and of the substrate after oxide removal by chemical etching. In this way, differences arisen from the irradiation procedure and possible changes of the $\mathrm{SiO}_{2} / \mathrm{SiC}$ structure in the course of oxidation could be studied.

\section{EXPERIMENTAL DETAILS}

Si-faced nitrogen doped $6 \mathrm{H}-\mathrm{SiC}$ samples cut from a wafer with resistivity $0.075 \Omega \mathrm{cm}$ supplied by Cree, Inc. were used 
TABLE I. Oxide thicknesses grown on the different samples and percentage of the irradiated layer consumed by oxidation. The $\mathrm{SiO}_{2} / \mathrm{SiC}$ interface roughness of each sample determined by AFM (after etching away the oxide) are also given.

\begin{tabular}{lccccc}
\hline \hline Sample & Irradiation & $\begin{array}{c}\text { Oxidation time } \\
(\mathrm{min})\end{array}$ & $\begin{array}{c}\text { Oxide thickness } \\
(\mathrm{nm})\end{array}$ & $\begin{array}{c}\text { Consumption of the } \\
\text { irradiated layer }(\%)\end{array}$ & $\begin{array}{c}\mathrm{SiO}_{2} / \mathrm{SiC}_{\text {interface }} \\
\text { roughness }(\mathrm{nm})\end{array}$ \\
\hline \multirow{2}{*}{$N 360$} & No & 360 & 25 & - & 0.76 \\
$I 60$ & Yes & 60 & 48 & 15 & 3.6 \\
$I 150$ & Yes & 150 & 160 & 45 & 7.2 \\
$I 720$ & Yes & 720 & 307 & 100 & 1.4 \\
\hline \hline
\end{tabular}

in this experiment. After a standard RCA cleaning, samples were dipped for $30 \mathrm{~s}$ in a $5 \% \mathrm{HF}$ solution in ethanol, followed by a $30 \mathrm{~s}$ ethanol rinsing aiming at removing the native oxide. Immediately after this etching procedure the samples were introduced in the ion implantation chamber which was pumped down to $5 \times 10^{-7}$ mbar. Irradiation was performed with $\mathrm{Ar}^{+}$at an energy of $170 \mathrm{keV}$ and fluence of $1.1 \times 10^{15} \mathrm{~cm}^{-2}$ in a $500 \mathrm{kV}$ HVEE ion implanter, yielding a superficial amorphized layer observed by Rutherford backscattering spectrometry in channeling geometry.

Four different types of samples were investigated. Samples designated by $N 360$ were nonirradiated SiC substrates which underwent wet oxidation for $360 \mathrm{~min}$ at $1100^{\circ} \mathrm{C}$, using $\mathrm{N}_{2}$ bubbled through deionized water kept at $95^{\circ} \mathrm{C}$. Samples $I 60, I 150$, and $I 720$ were irradiated substrates oxidized in the same temperature and pressure conditions as samples $N 360$ for 60,150 , and $720 \mathrm{~min}$, respectively (see Table I).

RBS in channeling geometry ( $c$-RBS) analyses (detection angle was $170^{\circ}$ ) were performed in a $3 \mathrm{MV}$ HV Tandetron ion accelerator with $2 \mathrm{MeV} \mathrm{He}^{+}$ions aligned in the $\langle 0001\rangle$ crystal axis in order to determine the oxide thickness in different samples and to infer about the residual damage in the $\mathrm{SiC}$ substrate. The areal density of $\mathrm{O}$ in the films was determined from the areas of the corresponding $\mathrm{O}$ signals in the RBS spectra, calibrated against a $\mathrm{SiO}_{2}$ film reference (5.70 $\times 10^{17} \mathrm{O} \mathrm{cm}^{-2}$ ). Film thicknesses were obtained using the equivalent relationship $10^{15} \mathrm{O} \mathrm{cm}^{-2} \leftrightarrow 0.226 \mathrm{~nm}$ of $\mathrm{SiO}_{2}$, obtained assuming an oxide density of $2.21 \mathrm{~g} \mathrm{~cm}^{-3}$, valid for $\mathrm{SiO}_{2}$ thermally grown on $\mathrm{Si}$. Since oxides thermally grown on $\mathrm{Si}$ and on $\mathrm{SiC}$ are very similar, this assumption should not lead to appreciable errors. The values of oxide thicknesses obtained in this way are shown in Table I. After this procedure, the oxide surface morphology of the different samples was probed using AFM, performed on a Digital Instruments Nanoscope IIIa in tapping mode. After etching away the oxide with a $8: 2 \mathrm{H}_{2} \mathrm{O}: \mathrm{HF}(50 \%)$ solution, a new set of channeled $c$-RBS measurements and AFM scans were carried out in all samples.

The chemical environment of $\mathrm{Si}$ in the oxide was investigated as a function of depth in samples N360, I150, and I720. The oxide was progressively thinned by immersion of each sample in a 50:1 $\mathrm{H}_{2} \mathrm{O}: \mathrm{HF}(50 \%)$ solution with a wellcharacterized removal rate $(1 \AA / s) .{ }^{14}$ After each etching step, stopped by water rinsing, XPS spectra were recorded using $\mathrm{Mg} K \alpha$ excitation $(h \nu=1253.6 \mathrm{eV})$ in an OMICRON
UHV station based on an EA125 hemispherical analyzer. Detection angle $\theta$ of the photoelectrons with respect to the normal to the sample surface (take-off angle) was fixed at $45^{\circ}$. The step-by-step etching procedure was carried out until no change in the Si $2 p$ region spectrum was observed. Au $4 f_{7 / 2}$ photoelectrons from a foil covering part of the sample were used as the binding energy $(\mathrm{BE})$ reference $(83.8 \mathrm{eV})$.

\section{RESULTS AND DISCUSSIONS}

RBS spectra obtained in channeling geometry of all samples after etching away the oxides are presented in Fig. 1. RBS spectra from a $6 \mathrm{H}-\mathrm{SiC}$ virgin crystal and from a sample just after $\mathrm{Ar}^{+}$irradiation are also plotted for comparison. The residual damage after oxidation of samples $I 60$ and $I 150$ can be clearly observed by the higher yield next to the $\mathrm{Si}$ energy leading edge in comparison to the channeled spectrum from the virgin crystal. Different thicknesses of the residual damaged layer are due to different oxidation times. Comparing the estimated amounts of Si present in the oxide with the amount of $\mathrm{Si}$ in the irradiated layer of the asirradiated sample, ${ }^{21}$ one can observe that the oxidation times used for samples $I 60, I 150$, and $I 720$ consumed 15,45 , and $100 \%$ (within an error of 10\%) of the amorphized layers,

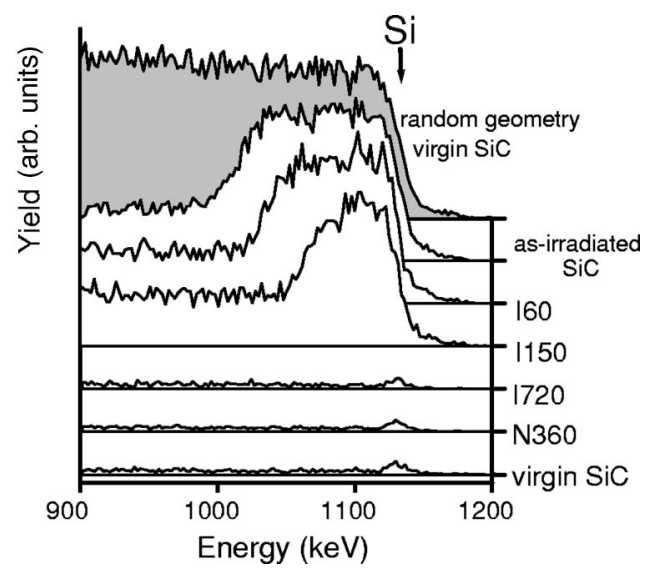

FIG. 1. Rutherford backscattering spectrometry spectra in random (shaded curve) and channeling (nonshaded curves) geometries of samples $N 360, I 60, I 150$, and $I 720$, after removal of the oxide layer by HF etching. Spectra of a virgin SiC sample and of the same sample just after ion irradiation are also plotted for comparison. The vertical arrow indicates the energy position of $\mathrm{Si}$ at the sample surface. 


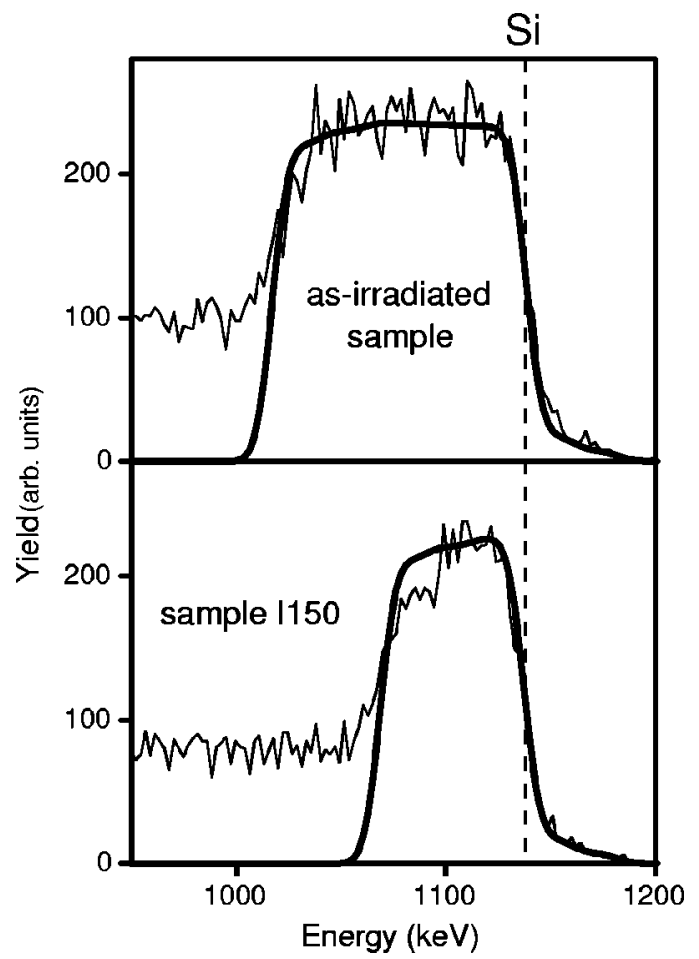

FIG. 2. Rutherford backscattering spectrometry in channeling geometry spectra of the irradiated $\mathrm{SiC}$ substrate (top) and of sample I150 after oxide removal (bottom) simulated using the RUMP code (Ref. 15). Thicker lines correspond to the simulation curve, while thinner ones, to experimental data. The vertical dashed line indicates the energy position of $\mathrm{Si}$ at the sample surface.

respectively. Performing similar calculations with data from the sample of Ref. 13 we concluded that, in that work, approximately half of the damaged layer was consumed, resembling sample $I 150$ of the present work.

Another process taking place during oxidation of irradiated $\mathrm{SiC}$ can be observed when simulating the $c$-RBS spectra of the irradiated substrate and of sample $I 150$ (after oxide etching) with the RUMP code, ${ }^{15}$ as shown in Fig. 2. In the first case, the simulation agrees with experimental data of the amorphized layer, but in the spectrum from sample $I 150$ the disagreement between experimental and simulated curves evidences a higher degree of ion channeling near the interface between the amorphized layer and the single crystal, resulting from partial crystallization of the amorphized layer. In a previous work, ${ }^{16}$ crystallization of the implanted region during oxidation was also observed: selected-area electron diffraction (SAED) measurements evidenced an epitaxial structure of $6 \mathrm{H}$ then another one of $3 \mathrm{C}-\mathrm{SiC}$ polytype close to the interface of the implanted layer with the $6 \mathrm{H}-\mathrm{SiC}$ substrate, and then hexagonal and cubic $\mathrm{SiC}$ grains in the uppermost part of the layer. They also observed by cross-sectional transmission electron microscopy (XTEM) that the top and bottom interfaces of the oxide grown on this crystallized layer were rough.

Considering these findings, we determined the roughness of both oxide and $\mathrm{SiC}$ substrate (after chemical removal of the oxide layer) surfaces. Figure 3 shows images of all

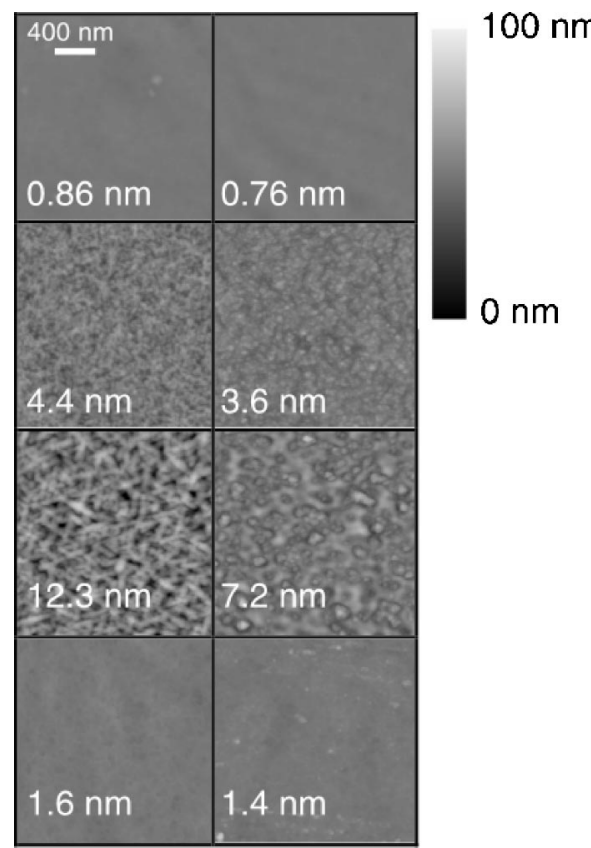

FIG. 3. Tapping mode AFM images of the oxide surfaces (left column) and exposed substrates after oxide removal (right column) from samples $N 360, I 60, I 150$, and $I 720$ (top $\rightarrow$ bottom). The calculated RMS roughness values are listed together with the respective images.

samples with their respective calculated root-mean-square (RMS) roughness values. Sample N360, the oxidized virgin crystal, has the smoothest surfaces, with roughnesses almost equal to the virgin crystal prior to oxidation $(0.66 \mathrm{~nm}$, not shown). Samples $I 60$ and $I 150$ evidence a large increase in roughness values as compared to sample $N 360$. The origin of the observed morphology changes is attributed to the crystallization of the amorphous layer underneath the oxide, leading to a nonuniform oxidation front of the growing oxide. The longer the oxidation time undergone by the sample, the higher the degree of recrystallization of the remaining damaged layer. As a result of this process, roughness of sample $I 150$ is greater than that of sample I60. Morphology is changed in the case of sample 1720 , whose surfaces are much smoother, deviating from the previous tendency of roughness increase. In this case the whole bombarded layer was consumed during oxidation, such that the previously existing grains of the polycrystal were totally oxidized, resulting in the observed smoothening of both surfaces. Thus, further oxidation should not lead to increasing roughness since a single crystal is being consumed for oxide growth.

XPS results aiming at probing the chemical environment of $\mathrm{Si}$ are shown in Figs. 4-7. Owing to the complexity of photoelectron signals, a fitting procedure routine for the $\mathrm{Si} 2 \mathrm{p}$ region was adopted, which consisted of assuming two components, one related to $\mathrm{SiO}_{2} \quad\left(\mathrm{Si}^{\mathrm{ox}}\right)$ $(\mathrm{FWHM}=1.5 \mathrm{eV}, 80 \%$ Gaussian $+20 \%$ Lorentzian $)$ and the other to $\mathrm{SiC} \quad\left(\mathrm{Si}^{\mathrm{SiC}}\right) \quad(\mathrm{FWHM}=1.7 \mathrm{eV}, 80 \%$ Gaussian $+20 \%$ Lorentzian). The width and shape of each component were fixed using values obtained from fitted regions of a $\mathrm{SiO}_{2}$ thick film on $\mathrm{SiC}$ and a virgin $\mathrm{SiC}$ sample, respectively. 


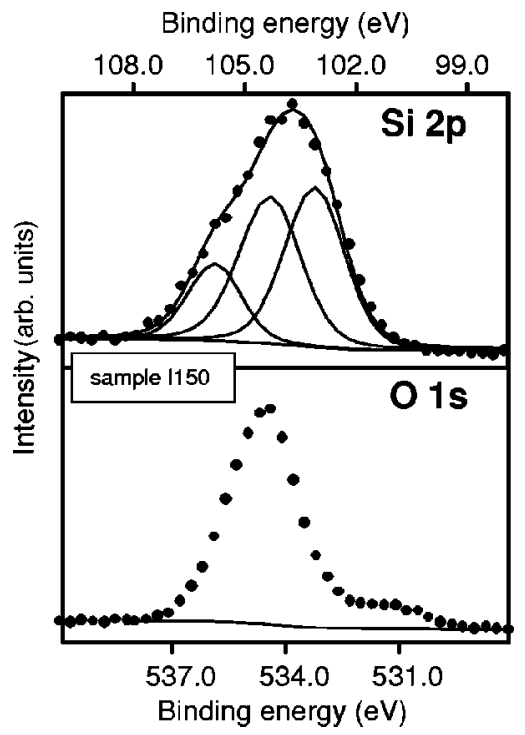

FIG. 4. Si $2 p$ (top) and O $1 s$ (bottom) regions of XPS spectrum of sample $I 150$ after $1700 \mathrm{~s}$ of etching. Points represent experimental data. Solid curves correspond to fitting components, Shirley background, and their sum.

Two binding energy (BE) constrains were primarily adopted: (i) these two $\mathrm{Si} 2 p$ components are separated by $2.7 \mathrm{eV}$ and (ii) $\mathrm{Si} 2 p$ and $\mathrm{O} 1 s$ components related to $\mathrm{SiO}_{2}$ are separated by $429.5 \mathrm{eV}$. These initial approaches were used in fitting spectra from samples N360, I150, and I720 submitted to step-by-step etching. In the case of samples $I 720$ and N360, no additional components were needed in the fitting proce-

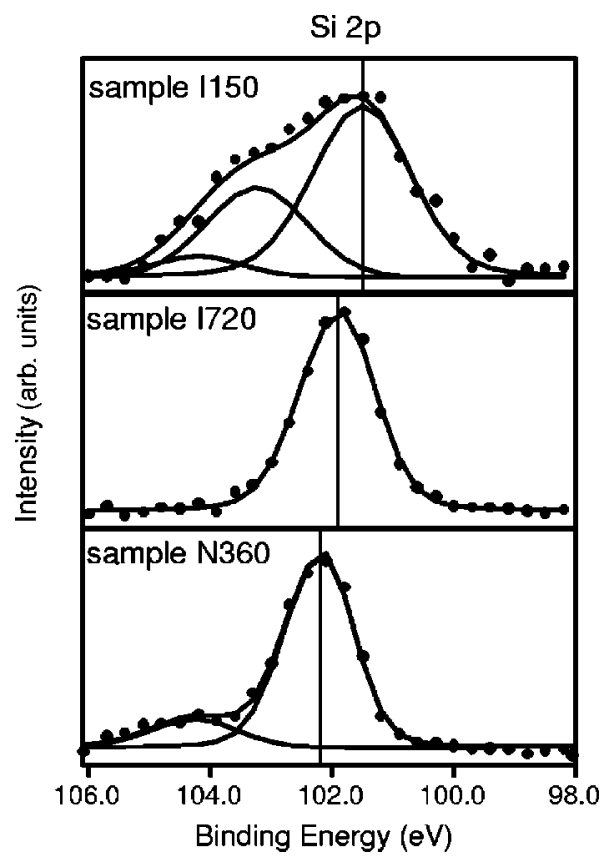

FIG. 5. Si $2 p$ regions of XPS spectra of samples $I 150$ (top), $I 720$ (center), and $N 360$ (bottom) after removal of most oxide layers. Points represent experimental data. Solid curves correspond to fitting components and their sum. Shirley background was subtracted from all regions. Vertical lines indicate the $\mathrm{BE}$ of the $\mathrm{Si}^{\mathrm{SiC}}$ component in each sample. dure but the proposed binding energy separation between the $\mathrm{Si}^{\mathrm{ox}}$ and $\mathrm{Si}^{\mathrm{SiC}}$ components had to be changed and depended on oxide thickness. In the case of sample $I 150$, however, the modifications were more pronounced. Figure 4 shows the $\mathrm{Si}$ $2 p$ and $\mathrm{O} 1 s$ regions of the spectrum of sample $I 150$ after a total accumulated etching time of $1700 \mathrm{~s}$, which exposed the $\mathrm{SiO}_{2} / \mathrm{SiC}$ interfacial region. In addition to the two components used in the first fitting trial, another component with an intermediate $\mathrm{BE}$ had to be added. This new component $\left(\mathrm{Si}^{\mathrm{OC}}\right)$ was attributed to the formation of $\mathrm{Si}$ oxycarbides $\left(\mathrm{SiC}_{x} \mathrm{O}_{y}\right)$, compounds where $\mathrm{Si}$ is bonded to a variable number of $\mathrm{O}$ and $\mathrm{C}$ atoms. This kind of compound was already observed in the interfacial region of thermal oxides grown on crystalline $\mathrm{SiC}^{8,17,18}$ Concerning the $\mathrm{O} 1 s$ region of the spectra, the predominant contribution to it is a component related to oxygen in $\mathrm{SiO}_{2}\left(\mathrm{O}^{\mathrm{ox}}\right)$, centered at $534.5 \mathrm{eV}$ in the case of Fig. 4. In order to obtain good fits, the BE differences between $\mathrm{Si}^{\mathrm{SiC}}$ and $\mathrm{Si}^{\mathrm{ox}}$ components had to be changed as a result of BE shifts in both components, which will be analyzed further in Figs. 5 and 6. However, it is worth to mention that the binding energy constrain of $429.5 \mathrm{eV}$ between $\mathrm{Si}^{\mathrm{ox}}$ and $\mathrm{O}^{\mathrm{ox}}$ components was kept in fittings of all samples and of all thicknesses.

Figure 5 shows Si $2 p$ regions spectra of samples $I 150$, I720, and $N 360$ after being etched in a $8: 2 \mathrm{H}_{2} \mathrm{O}: \mathrm{HF}(50 \%)$ solution for $1 \mathrm{~min}$. After this step, the oxide layer should have been completely removed in all samples and the Si $2 p$ signals should be due solely to $\mathrm{SiC}$. However, reoxidation of the samples due to their exposure to air between the etching procedure and their introduction in the UHV chamber was observed by the appearance of another component around $104 \mathrm{eV}$. In the case of sample $I 150$, its Si $2 p$ region spectrum evidenced a large contribution of $\mathrm{Si}^{\mathrm{OC}}$ in addition to the other two components. This behavior was attributed to the $\mathrm{SiO}_{2} / \mathrm{SiC}$ interface roughness, observed by AFM, and will be further discussed with Fig. 7. The Si $2 p$ regions from the other two samples presented different contents of $\mathrm{Si}^{\text {ox }}$ due to different exposure times to air. Comparing the BE's of the $\mathrm{Si}^{\mathrm{SiC}}$ component, one observes different values. Other authors ${ }^{19}$ also observed distinct $\mathrm{Si}^{\mathrm{SiC}} \mathrm{BE}$ 's recorded from $\mathrm{SiC}$ surfaces that underwent different sacrificial oxidation preparation procedures. They attributed this change to the modification of both the density of surface states and their position within the band gap. In view of that, the observed change in $\mathrm{BE}$ may be related to electronic changes of the substrate underneath the oxide. Thus, ion irradiation yields (in addition to morphological differences already observed by AFM and $c$-RBS) an electronic modification of the semiconductor region close to the $\mathrm{SiO}_{2} / \mathrm{SiC}$ interface. Moreover, the observed energy shift depends on how much of the amorphous layer was oxidized: as the oxidation front approaches the single crystal, the closer to the nonirradiated sample is the BE value of the $\mathrm{Si}^{\mathrm{SiC}}$ component.

The $\mathrm{BE}$ of the $\mathrm{Si}^{\mathrm{ox}}$ components from samples $N 360$, $I 150$, and $I 720$ as a function of the oxide thicknesses (etched step-by-step in the HF solution mentioned in Sec. II) is shown in Fig. 6. Curves were aligned by the point corresponding approximately to the oxide/SiC interface. A depth scale was built based on the etching time scale. In this ap- 


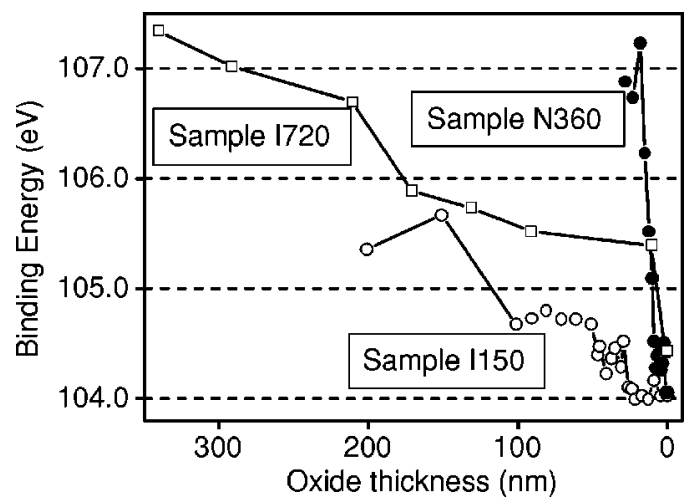

FIG. 6. Binding energy of the $\mathrm{Si}^{\mathrm{ox}}$ component of the $\mathrm{Si} 2 p$ regions as a function of the remaining oxide thickness after successive HF etching steps of samples $N 360$ (solid circles), I720 (open squares), and $I 150$ (open circles). The depth scale was obtained assuming a fixed etching rate of the HF solution.

proach, the etching rate was assumed constant through the whole oxide length. This is an approximation, since this rate changes, particularly in the $\mathrm{SiO}_{2} / \mathrm{SiC}$ interfacial region. However, this effect will not change the essence of our conclusions. The $\mathrm{BE}$ variation of this component can not be attributed to the detection of different compounds, since a synchronization of $\mathrm{BE}$ shifts of $\mathrm{SiO}_{2}$ components from $\mathrm{Si} 2 p$ and $\mathrm{O} 1 s$ regions is always observed. All curves evidence a similar trend, namely, a lowering of the BE as the interfacial region is approached. In addition, the BE values corresponding to sample $I 720$ are always higher than those of sample I150 for the same oxide thickness. Next to its oxide surface

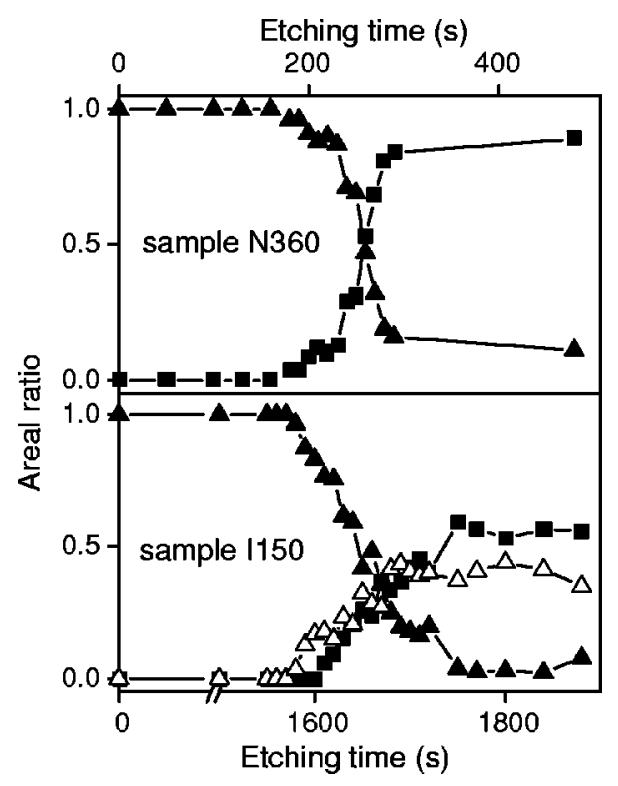

FIG. 7. Fitting results of the Si $2 p$ regions of XPS spectra of sample $N 360$ (top) and sample $I 150$ (bottom). Horizontal axes correspond to the total etching time undergone by each sample while in the vertical axis is the areal ratio between the component at issue and the whole $\mathrm{Si} 2 p$ region area. The components are related to $\mathrm{SiO}_{2}$ (solid triangle), $\mathrm{SiC}$ (solid square), and $\mathrm{SiC}_{x} \mathrm{O}_{y}$ (open triangle). region, sample $I 720$ evidences $\mathrm{BE}$ values comparable to those observed in the analogous region of sample $N 360$.

Differences between oxides thermally grown on $\mathrm{Si}$ and on $\mathrm{SiC}$ were investigated ${ }^{20}$ previously, and the authors claimed that the observed $\mathrm{BE}$ difference between $\mathrm{Si}^{\mathrm{ox}}$ components of oxides grown on $\mathrm{Si}$ and on $\mathrm{SiC}$ were due to structural differences associated with the formation of the dielectric film: $\mathrm{SiO}_{2}$ films thermally grown on $\mathrm{SiC}$ (with smaller $\mathrm{BE}$ ) appear to be under less stress than on Si (100) (with larger BE). The present results can be understood using the same reasoning developed in Ref. 20, namely, correlating BE values with the amount of stress. Thus, the oxide formed on sample $I 150$ is the least stressed one, since the $\mathrm{BE}$ of its $\mathrm{Si}^{\text {ox }}$ component is the lowest. This is in agreement with what is expected from the oxidation of a more disordered material, since the bombarded SiC layer should induce a lower strain in the oxide as compared to the single crystal. The observed differences in stress manifest the distinct degrees of crystallinity reached by the damaged layers of samples $I 150$ and $I 720$. The substrate underneath the oxide in sample $I 150$ recrystallized in a smaller extent than that of sample 1720 . This last sample, due to the longer oxidation, had more time to recrystallize and consumed all bombarded layer by oxidation yielding an oxide on a nearly single crystalline substrate. Thus, consistently with Ref. 20, the $\mathrm{Si}^{\text {ox }} \mathrm{BE}$ at the $\mathrm{SiO}_{2} / \mathrm{SiC}$ interface of sample $I 720$ has values similar to those from sample $N 360$, the one with the oxide layer grown on a $c$-SiC substrate. This assumption is also reinforced by the results obtained by $c$-RBS and AFM.

Si $2 p$ regions of XPS spectra of samples $N 360, I 150$, and 1720 recorded after each etching step were fitted by the above mentioned procedure. The area of each component was normalized by the total area of the respective $\mathrm{Si} 2 p$ regions. These values were plotted as a function of the accumulated etching time in Fig. 7, yielding composition profiles throughout the oxide films. Data from sample $I 720$ are not shown since they are very similar to those of sample $N 360$. An approximate depth scale can be obtained assuming a constant etching rate as already described. The composition profile for sample $N 360$ evidences expected facts: $\mathrm{a} \mathrm{SiO}_{2}$ signal as the only component until a certain etching time, which decreases to a lower areal value due to progressive contribution from the substrate underneath the oxide. The lowest areal value of the $\mathrm{SiO}_{2}$ signal corresponds to the native oxide layer formed during sample exposure to air between successive analyses. The width of the transition region shown in Fig. 7 top $(\sim 10 \mathrm{~nm})$, defined by the range of etching times limited by near constant behavior of the components, is wider than the real $\mathrm{SiO}_{2} / \mathrm{SiC}$ interface due to variations in the etching rate and to the finite probing depth of XPS $(\sim 1.5 \mathrm{~nm})$. Composition profile of sample $I 150$ evidences a different interfacial region in comparison with sample $N 360$. Besides the additional curve related to $\mathrm{SiC}_{x} \mathrm{O}_{y}$ compounds, a wider transition region is observed $(\sim 18 \mathrm{~nm})$. The actual value is certainly lower, but it is anyway much larger than the one obtained from sample N360. We propose that the roughness of the $\mathrm{SiO}_{2} / \mathrm{SiC}$ interface (observed by AFM) is responsible for this artifact. Due to roughness, the photoelectrons detected are in fact probing regions at differ- 
ent distances relative to the interface and the resulting spectrum would be an average of regions more or less close to the $\mathrm{SiC}$ substrate. In addition to the wider transition region, the observed interfacial roughness gave rise to another artifact: the amplification of the signal from the $\mathrm{Si}^{\mathrm{OC}}$ component. $\mathrm{SiC}_{x} \mathrm{O}_{y}$ compounds were observed ${ }^{8}$ in much thinner oxides analyzed by angle-resolved XPS. In that work, clear signals of these compounds were only obtained with an experimental setup privileging the analysis of the sample near-surface region, using high take-off angles values $\left(>60^{\circ}\right)$. In the present study, the amplified sensitivity was provided by the increased roughness of the $\mathrm{SiO}_{2} / \mathrm{SiC}$ interface, which leads to an increased areal density of this interfacial probed region.

\section{CONCLUSIONS}

In summary, we investigated structural, compositional, and electronic characteristics of thermally grown oxide layers on ion irradiated $\mathrm{SiC}$ substrates. Several differences were observed in comparison with a nonirradiated sample. The most striking effect observed is the enhanced rate of oxidation: using the same oxidation conditions, much thicker oxides were obtained on the irradiated sample. In addition to the enhanced oxidation rate, the atomic scale processes arisen from ion bombardment, which can affect the electrical characteristics of the $\mathrm{SiO}_{2} / \mathrm{SiC}$ structure, were investigated. The roughnesses of both oxide surface and $\mathrm{SiO}_{2} / \mathrm{SiC}$ interface were greater for samples submitted to ion irradiation. XPS analyses of different samples, in which oxide films were step-by-step thinned by chemical etching, evidenced electronic and structural differences induced by the irradiation process. Indeed the $\mathrm{BE}$ shifts of the $\mathrm{Si}^{\mathrm{SiC}}$ component near the $\mathrm{SiO}_{2} / \mathrm{SiC}$ interface are different from those in the same region of oxidized virgin $\mathrm{SiC}$ wafers. Irradiation also gave rise to less stressed oxides, as evidenced by the analysis of the

*Electronic address: fernanda@iq.ufrgs.br

${ }^{1}$ C.M. Johnson et al., IEEE Proc. Circuits Devices Syst. 148, 101 (2001).

${ }^{2}$ W. Wondrak, R. Held, E. Niemann, and U. Schmid, IEEE Trans. Ind. Electron. Control Instrum. 48, 307 (2001).

${ }^{3}$ C. Raynaud, J. Non-Cryst. Solids 280, 1 (2001).

${ }^{4}$ M. Iwami, Nucl. Instrum. Methods Phys. Res. A 466, 406 (2001).

${ }^{5}$ V.R. Vathulya, D.N. Wang, and M.H. White, Appl. Phys. Lett. 73, 2161 (1998).

${ }^{6}$ C.I. Harris and V.V. Afanas'ev, Microelectron. Eng. 36, 167 (1997).

${ }^{7}$ C. Onneby and C.G. Pantano, J. Vac. Sci. Technol. A 15, 1597 (1997).

${ }^{8}$ C. Radtke, I.J.R. Baumvol, J. Morais, and F.C. Stedile, Appl. Phys. Lett. 78, 3601 (2001).

${ }^{9}$ M.R. -Chudoba, P. Soukiassian, C. Jaussaud, and S. Dupont, Phys. Rev. B 51, 14300 (1995).

${ }^{10}$ R. Nipoti, M. Madrigali, and A. Sambo, Mater. Sci. Eng., B 6162, 475 (1999).

${ }^{11}$ T. Yoneda, T. Nakata, M. Watanabe, and M. Kitabatake, Mater. Sci. Eng., B B 61-62, 502 (1999).

${ }^{12}$ D. Alok and B.J. Baliga, J. Electrochem. Soc. 144, 1135 (1997).
$\mathrm{BE}$ values of $\mathrm{Si}^{\mathrm{ox}}$ components. The different structure of the semiconductor underneath the oxide and the irradiationinduced roughnesses may be responsible for the bad electrical characteristics of devices obtained following this route. In addition to the differences attributed to irradiation itself, remarkable changes became evident when comparing irradiated substrates oxidized for different times. Distinct degrees of recrystallization were reached by the remaining damaged layer, which is progressively consumed in the course of oxidation. This recrystallization process gives rise to an increasing roughness of the oxide surface and $\mathrm{SiO}_{2} / \mathrm{SiC}$ interface. When the whole damaged region is consumed, roughness decreases since further material consumption for oxide growth is now single crystalline. Hence, the electrical characteristics of the final device should depend on the thickness of this remaining damaged layer, which is a function of the oxidation time. A previous work ${ }^{13}$ concerning electrical characterization of metal-oxide-semiconductor structures built on irradiated $\mathrm{SiC}$ considered this route not suitable for the growth of gate oxides. However, in that work, only part of the irradiated layer $(50 \%)$ was oxidized, which certainly influenced the observed electrical characterization results. Thus, the present findings do not exclude ion irradiation as a processing tool while pointing to the need of a total consumption of the damaged layer as an essential requirement for device quality oxides thermally grown on irradiated $\mathrm{SiC}$. Following this reasoning, thick oxides grown with high oxidation rates and presenting the required electrical characteristics are expected.

\section{ACKNOWLEDGMENTS}

Work partially supported by CNPq, PADCT, and FAPERGS.
${ }^{13}$ D. Alok, B.J. Baliga, and P.K. McLarty, IEEE Electron Device Lett. 15, 424 (1994).

${ }^{14}$ M.B. Johnson, M.E. Zvanut, and O. Richardson, J. Electron. Mater. 29, 368 (2000).

${ }^{15}$ L.R. Doolittle, Nucl. Instrum. Methods Phys. Res. B 9, 334 (1985).

${ }^{16}$ R. Nipoti and A. Parisini, Philos. Mag. B B 80, 647 (2000).

${ }^{17}$ B. Hornetz, H.J. Michel, and J. Halbritter, J. Mater. Res. 9, 3088 (1994).

${ }^{18}$ F. Amy, P. Soukiassian, Y.K. Hwu, and C. Brylinski, Phys. Rev. B 65, 165323 (2002).

${ }^{19}$ A. Koh, A. Kestle, C. Wright, S.P. Wilks, P.A. Mawby, and W.R. Bowen, Appl. Surf. Sci. 174, 210 (2001).

${ }^{20}$ G.G. Jernigan, R.E. Stahlbush, and N.S. Saks, Appl. Phys. Lett. 77, 1437 (2000).

${ }^{21}$ The amount of Si present in each oxide film was obtained from the amount of $\mathrm{O}$ determined as described in the experimental details section. This last quantity was divided by two (assuming a stoichiometric layer of $\mathrm{SiO}_{2}$ ) yielding the areal density of $\mathrm{Si}$. To determine the amount of $\mathrm{Si}$ in the irradiated layer before oxidation, we simulated the channeled RBS spectrum of the asirradiated sample as shown in Fig. 2. Simulation using the RUMP 
(Ref. 15) code consists of assuming a certain areal density of a material with a defined stoichiometry and stopping power; analyzed under certain experimental conditions (beam energy, beam ion, incident charge, detector geometry, resolution, and solid angle). Then, the program generates a theoretical spectrum that should be compared to experimental data. In this way we determined the areal density of $\mathrm{Si}$ in the amorphized layer, since in the single crystal the alignment of atoms respective to the incident beam makes the detected ion yield to decrease. 